\title{
Biochemical changes in the liver, kidney and serum of rats exposed to ethanolic leaf extract of Ziziphus spina-christi
}

\author{
Sabah M. Khaleel ${ }^{1}$, Rana A. Almuhur ${ }^{1}$, Taghleb M.F. Al-Deeb ${ }^{1, *}$ and Adnan S. Jaran ${ }^{2}$ \\ ${ }^{1}$ Department of Biological Science, Al-Bayt University, Mafraq, Jordan; ${ }^{2}$ Department of Medical Laboratory Science, Al-Bayt University, \\ Mafraq, Jordan
}

Received: June 6, 2020; Revised: Nov 18, 2020; Accepted: Nov 28, 2020

\begin{abstract}
Ziziphus spina-christi has been used in traditional herbal medicine for the treatment of fever and inflammatory conditions. However, few studies had assessed its toxicological effects. This study was designed to investigate the effect of ethanolic leaf extract of $Z$. spina-christi on biochemical markers of kidney and liver functions. Fourteen male Wistar albino rats were randomly assigned into two groups. Group I was the control group while group II received oral dose of $400 \mathrm{mg} / \mathrm{kg}$ ethanolic leaf extract daily for 14 days. On the $15^{\text {th }}$ day of treatment, rats were sacrificed and some biochemical parameters were evaluated. Then, liver, kidney and heart were taken, weighed and relative organ weight was calculated. Oral dose of leaf extract significantly $(\mathrm{P}<0.05)$ increased rats' serum levels of lactate dehydrogenase and total bilirubin while had no significant effect on the other liver enzymes. On the other hand, treatment with the extract significantly increased insulin level, decreased triglyceride level and had no significant effect on the other lipid profile components. Kidney function parameters were not significantly affected by the extract treatment. However, relative liver and heart weight ratios were significantly reduced in $(\mathrm{P}<0.05)$ treated rats. The results of this study have shown that oral administration of the ethanolic leaf extract of $Z$. spina-christi did not have deleterious effect on liver, kidney and serum biochemical parameters at the dosage used.
\end{abstract}

Keywords: Ziziphus spina-christi, lipid profile, Kidney function, Liver function, Wistar rats

\section{Introduction}

Many people from diverse cultures use traditional plants as a source of folkloric medicines. The presence of high concentrations of phytochemical compounds in these plants promotes attention to evaluate their potential healthpromoting effects (WHO, 1998, Pieme et al., 2006). Since synthetic drugs are not often affordable or safe, many studies were performed to seek new natural bioactive molecules, which are considered to be safe and without side effects (Kunle et al., 2012; Mostafavinia et al., 2016).

Lack of quality control and scientific evidence for the efficacy and safety of medicinal plants are major concerns that have been raised recently; since many plants were consumed at higher dosages and for long time, they could be toxic and directly impact the physiological function of the body (Nuhu and Aliyu (2008; Herrine, 2018). Therefore, there is a need for more scientific evaluations on their efficiency and potential toxicity.

Ziziphus spina-christi belongs to the family Rhamnaceae. It is commonly called sedr. It has been used as a medicine in Arabic herbal traditions, especially in Jordan (Abu-Hamdah et al, 2005; Khaleel et al., 2016). The most common therapeutic properties of the Ziziphus are antioxidant, anti-cancer, antibacterial, antivirus and anti-inflammation properties (Khaleel et al., 2019). The major active components of $Z$. spina christi are flavonoids, tannins and phenolic compounds (Khaleel et al., 2018). Despite the wide spread use of this plant, there are a few specific scientific reports on the evaluation of its toxicological effects. Therefore, this study was designed to assess the kidney and liver function indices in male Wistar albino rats administered ethanolic leaves extract of $Z$. spina-christi. Serum biochemical parameters, body and organ weight changes were also screened.

\section{Materials And Methods}

\subsection{Preparation of crude plant extracts}

Ziziphus spina-christi leaves (herbarium collection number 3543) were collected from different locations of Jordan valley in spring. The leaves were air dried, ground into a powder and soaked in $75 \%$ ethanol. The plant material was then shaken overnight at $\left(30^{\circ} \mathrm{C}\right)$ on a shaker for $48 \mathrm{hrs}$, then filtered, and dried by rotary evaporator and weighed (Khaleel, 2013).

\subsection{Experimental Animals and Dosing}

Fourteen male Wistar albino rats weighing between 185 and 245 g were obtained from the Department of Biological Science, Faculty of Science, Yarmouk University, Jordan. The rats were divided into two equal groups. Each group was kept in a plastic cage and housed

\footnotetext{
* Corresponding author e-mail: taghleb@aabu.edu.jo.
} 
in a well ventilated $12 \mathrm{~h}$ light and dark cycle. Commercial standard diet and water was supplied for 14 days. This study was performed according to the protocol of animal experiments and confirmed by the research and ethics committee of the department of biological sciences at $\mathrm{Al}$ al Bayt University, Mafraq, Jordan.

For a period of 14 consecutive days, experimental animals orally received $Z$. spina-christi ethanolic leaf extract ( $400 \mathrm{mg} / \mathrm{kg})$, whereas control group orally received normal saline for the same period (Bannoth et al., 2015) .

\subsection{Body and organs weights}

Animals were individually weighed at the beginning and at the end of the experiment using an electronic weighing balance. Body weight change of rats in each group was calculated and expressed in percentage (\%). Liver and kidney were harvested and weighed, from which the relative liver and kidney weights per $100 \mathrm{~g}$ body weight of rat was calculated according to the following equation:

Relative organ weight=[organ weight (g)/body weight $(\mathrm{g})] \times 100$

\subsection{Blood sampling}

Animals were sacrificed on the $15^{\text {th }}$ day by cervical dislocation. Blood was collected in a wax embedded tube and serum was separated by centrifugation at $5000 \mathrm{rpm}$ for 10 min and collected in a different tube and kept in freezer till the time of assay.

\subsection{Biochemical analysis}

Different serum biochemical parameters were determined using commercially available diagnostic kits from Biosystems S.A. Costa Brava, Barcelona (Spain). Serum samples were analyzed for the levels of aspartate aminotransferase (AST), alanine aminotransferase (ALT), alkaline phosphatase (ALP), lipase, and lactate dehydrogenase, and for the levels of glucose, insulin, lowdensity lipoproteins (LDL), high-density lipoproteins (HDL), total protein, creatinine, cholesterol, triglyceride, total bilirubin, uric acid and urea. All tests were analyzed according to the manufacturer's instructions.

\subsection{Statistical analysis}

Data were analyzed using two-sample t-test. Values were expressed as means \pm SD of three replicates. A probability value $\mathrm{P}<0.05$ was considered to be statistically significant.

\section{Results}

\subsection{Effects of Ziziphus leaf extract on liver function parameters in rats}

Following oral administration of $400 \mathrm{mg} / \mathrm{kg}$ doses of $Z$. spina christi, serum ALP level was reduced compared to the control group. However, ALP level wasn't significantly different between treated group and the control group. ALT and AST levels were not significantly $(\mathrm{P}>0.05)$ increased in treated rats. On the other hand, the treated rats showed a significant $(\mathrm{p}<0.05)$ elevation of LDH and total bilirubin levels (Figure 1).
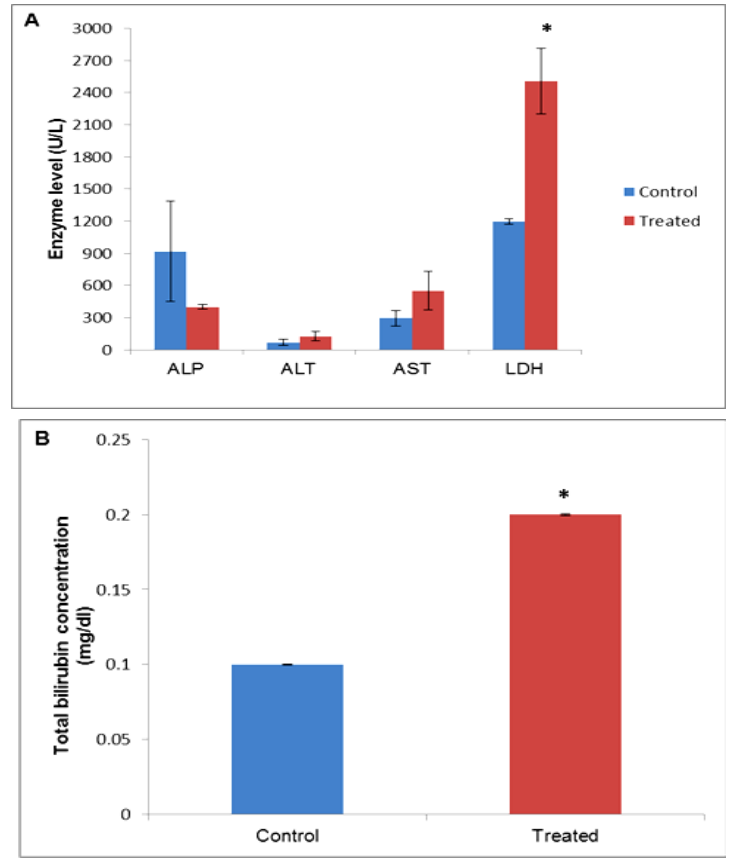

Figure 1. Liver enzymes (A) and total bilirubin (B) levels in control and extract-administered (treated) rats. Values were reported as mean $\pm \mathrm{SD}\left(\mathrm{n}=3\right.$ replicates). Asterisk $\left(^{*}\right)$ indicates a statistical significance $(\mathrm{P}<0.05)$.

\subsection{Effects of Ziziphus leaf extract on the kidney function parameters and total protein concentration in rats}

The effects of the plant extract on the kidney functions of the rats are revealed in Figure 2. The treated and control rats showed no significant difference $(\mathrm{p}<0.05)$ in the levels of urea, uric acid and creatinine (Figure 2A). However, there was a significant elevation in total protein concentration in treated group compared to the control group (Figure 2B).

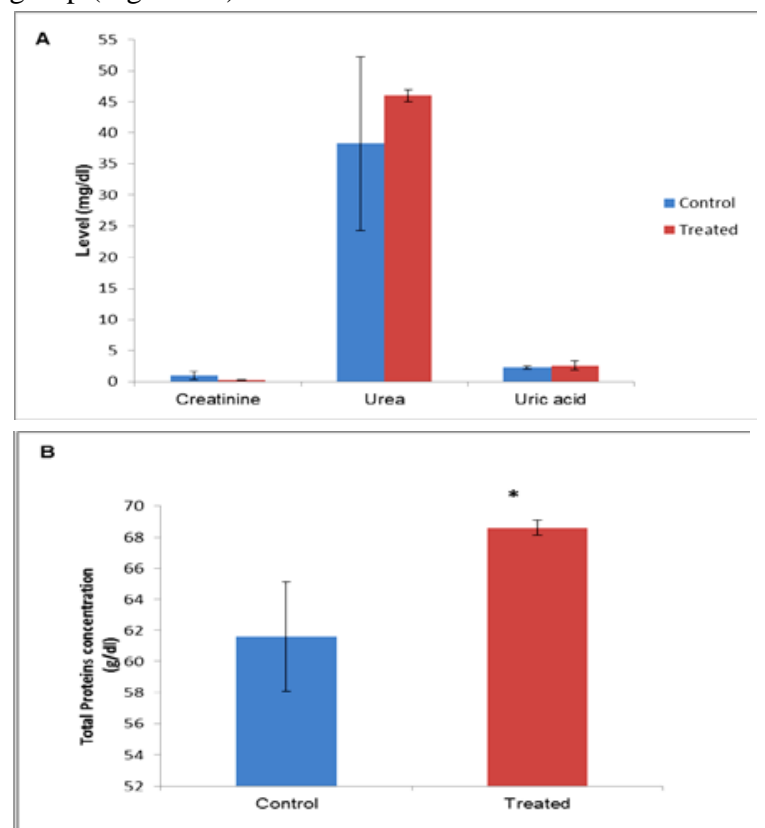

Figure 2. Creatinine, urea, uric acid levels (A) and total protein concentration (B) in control and extract administered (treated) rats Values were reported as mean $\pm \operatorname{SD}(\mathrm{n}=3)$. Asterisk $\left(^{*}\right)$ indicates a statistical significance $(\mathrm{P}<0.05)$. 
3.3. Effect of Ziziphus leaf extract on serum glucose and insulin levels in non-fasting rats

Extract-administered rats (treated) showed reduction in glucose level, but this reduction wasn't significantly different from the control. On the other hand, treated rats showed a significant $(\mathrm{P}<0.05)$ increase in insulin level as compared with control group (Table 1).

Table 1. Serum glucose and insulin levels in control and extractadministered (treated) rats (non-fasting)

\begin{tabular}{lll}
\hline & CONTROL & Treated \\
\hline Glucose (mg/dl) & $149.6 \pm 8.5$ & $133.0 \pm 7.0$ \\
Insulin (ulU/mL) & $0.7 \pm 0.01$ & $0.80 \pm 0.02 *$ \\
\hline
\end{tabular}

Values were reported as mean \pm SD $(n=3)$. Asterisk $(*)$ indicates a statistical significance $(\mathrm{P}<0.05)$.

\subsection{Effect of Ziziphus leaf extract on serum lipid profile in rats}

As shown in Figure 3, extract-administered rats (treated) showed reduction in the levels of serum triglyceride, cholesterol and LDL, and increase in the levels of serum HDL and lipase, when compared with control group. However, only triglyceride reduction was significantly different $(\mathrm{P}<0.05)$ between treated rats and the control.
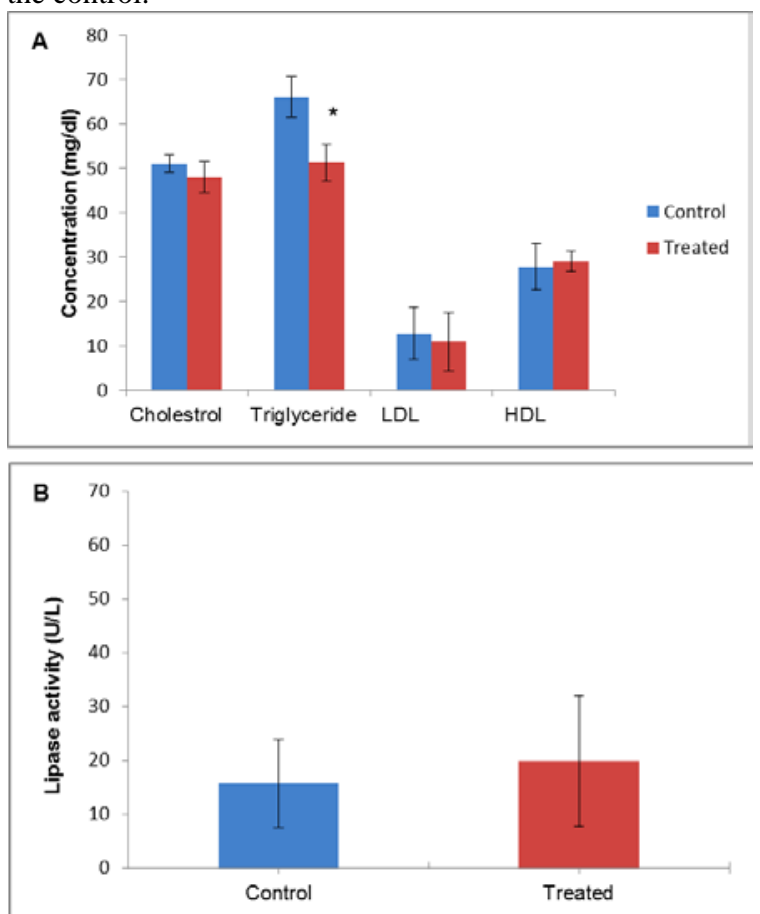

Figure 3. Cholesterol, triglyceride, LDL, HDL (A) and lipase level (B) in control and extract administered (treated) rats. Values were reported as mean $\pm \mathrm{SD}(\mathrm{n}=7)$. Asterisk $\left(^{*}\right)$ indicates a statistical significance $(\mathrm{P}<0.05)$.

\subsection{Effects of Ziziphus leaf extract on rat's body weight and relative organ weight.}

The mean body weights of rats treated with Ziziphus extract did not significantly $(\mathrm{P}<0.05)$ differ from controls (Table 2). However, the computed relative liver and heart weight ratios were significantly $(\mathrm{P}<0.05)$ decreased in treated rats (Table 2). This study illustrated that $400 \mathrm{mg} / \mathrm{kg}$ dose of Ziziphus extracts did not cause mortality in treated rats.
Table 2. Body weight change, and kidney, liver and heart indices in control and extract-administered (treated) rats.

\begin{tabular}{lll}
\hline & Control & Treated \\
\hline \% Weight change & $2.2 \pm 9.8$ & $17.4 \pm 13.6$ \\
Kidney index & $0.82 \pm 0.01$ & $0.70 \pm 0.071$ \\
Liver index & $4.1333 \pm 0.25$ & $3.1333 \pm 0.41^{*}$ \\
Heart index & $0.4933 \pm 0.04$ & $0.3367 \pm 0.07^{*}$ \\
\hline
\end{tabular}

Values were reported as mean $\pm \mathrm{SD}\left(\mathrm{n}=3\right.$ replicates). Asterisk $\left(^{*}\right)$ indicates a statistical significance $(\mathrm{P}<0.05)$.

\section{Discussion}

Many plants have a variety of properties and various biological components that can be used to treat various diseases. However, some medicinal plants have potential to impair a particular organ or organs' function in many ways (Nuhu and Aliyu, 2008; Herrine, 2018). This study was designed to assess the liver and kidney functions and serum biochemical indices in male Wistar albino rats administered ethanol leaves extract of $\mathrm{Z}$. spina christi, a Jordanian medicinal plant.

Liver enzymes such as ALT, AST, LDH and ALP were used to evaluate the hepatic dysfunction. The increased liver enzyme activities significantly reflect liver hepatocytes necrosis and cholestasis, and the high level of transaminases causes inflammation or hepatocellular disorders (Ali et al., 2005, Lavanaya et al., 2011 ). In the present study, the oral administration of the Ziziphus extract to rats resulted a significant increase in LDH level which coincided with insignificant reduction of glucose level in rats' serum (Table 1) suggesting that glucose may have gone through glycolysis to produce pyruvate/lactate. However, there was no significant difference in the glucose level between treated rats and control which might suggest that lactate was converted back to pyruvate then to glucose through gluconeogenesis (Andrew et al., 2005). On the other hand, insignificant change in the serum levels of ALT, AST and ALP levels was found in treated rats compared with the control (Figure 1). It can be observed that the changes in the three enzyme levels are not consistent to indicate liver damage. Although it was insignificant, the reduction in the levels of alkaline phosphatase (ALP), as observed in this present study, could be an indication of a good effects of Ziziphus extract on both liver and bone, since the two main sources of ALP are liver and bone. These findings are in agreement with the observations of Nwanjo (2007) and Ibrahim et al., (2016) when they reported insignificant increases in AST and ALT levels in serum to indicate non-hepatotoxic effects of the Phyllanthus nisruri leaf extract and tuber extracts of M. psuedopetalosa, respectively. Moreover, it was reported that ALT, AST and ALP levels insignificantly increased after treating Wistar rats with $500 \mathrm{mg} / \mathrm{kg}$ oral dose of Senecio aureus extract (Osuigwe and Margret, 2017). On the contrary, El-Desouky (2014) reported that oral administration of ethanolic Ziziphus mauritiana leaf extracts resulted in a significant decrease in level of ALT and AST enzymes in serum of $\gamma$-irradiated rats. The same observations were obtained in rats administered Anthyllis henoniana ethyl acetate flowers extract (Ben Younes et al., 2018). By contrast, rats treated with ethanolic leaf extract of Sorghum bicolor showed extremely significant $(\mathrm{P}<0.05)$ elevated levels of AST, 
ALT and ALP, which indicated intra-hepatic cell damage due to the extract administration (Ogunka-Nnoka et al., 2012). Elevated levels of serum bilirubin, as in certain diseases, is an index of liver damage and the major breakdown product of red blood cells (Baranano et al., 2002; Tano et al., 2013). Osuigwe and Margret (2017) found that $500 \mathrm{mg} / \mathrm{kg}$ oral dose of Senecio aureus extract significantly increased total bilirubin level in Wistar rats suggesting a possible liver damage in the treated rats. In the present study, compared with the control, the serum total bilirubin concentration increased significantly $(\mathrm{P}<0.05)$ in extract-administered rats with bilirubin concentration of $0.2 \pm 0.0 \mathrm{mg} / \mathrm{dL}$ (Figure 2). However, the serum total bilirubin values were still within the normal range (0.1-0.55 mg/dL).

Creatinine, urea and uric acid are major catabolic products of protein metabolism, and an elevation in their serum levels may indicate renal dysfunction (Renugadevi and Prabu, 2010; Mehrdad et al., 2011). Compared with the control (Figure 2), significant differences $(p<0.05)$ were not observed in the levels of creatinine, urea and uric acid in control and extract-administered rats. This indicates that the leaf extract had no negative effect on the kidneys. However, significant difference exists between the treated and control rats in the levels of serum total protein, which implies that the extracts might be able to improve protein synthesis. Determination of serum or plasma protein levels is clinically valuable and reflects major functional changes in kidney and liver functions (Leena et al., 2011). Low total protein levels may suggest liver and/or kidney disorders in which protein is not digested or absorbed properly. High total protein level may be seen in cases of chronic inflammation or liver infections (Ighodaro et al., 2015). These results of kidney functions are in agreement with the findings reported by Ashafa and Olunu (2011) on toxicity of leaf extracts of Marinda lucida.

According to the biochemical analysis, Ziziphus extract exhibited good improvement in biological evaluation of glucose, insulin and lipid profile. Wistar albino rats given leaf extracts of $Z$. spina-christi showed reduction in the levels of cholesterol, triglycerides, LDL, as well as elevation in the level of serum Insulin and HDL (Table 1, Figure 3). This effect may be due to the inhibition of dietary lipid absorption in the intestine, or low level of lipolysis and/or low activity of cholesterol biosynthesis enzymes which are under the insulin control (Ahmadvanda et al., 2012). A similar result was reported by Al-Qudah et al., (2016) who reported that treatment of diabetic rats with ginger extract produced a significant decrease in serum level of glucose, cholesterol and triglycerides and increase insulin and HDL-C levels when compared with untreated diabetic group. Furthermore, Seufi et al., (2019) found that $150 \mathrm{mg} / \mathrm{kg}$ oral dose of Morus nigra leaf extract significantly decreased serum triglycerides level in chlorpyrifos-exposed male Albino rats.

There was no significant change in the weights seen in all animals treated with ethanolic leaf extract of $Z$. spinachristi at a dose of $400 \mathrm{mg} / \mathrm{kg}$. However, the relative liver and heart weights of the animals treated with the plant extract significantly decreased (Table 2). The decrease in the weight of these organs might be due to the antinutritional bioactive components such as tannin probably present in the plant extract. (Alebachew et al., 2014).
Generally, the observed medicinal value of ethanolic extract of Ziziphus might be due to the phytochemicals composition of the extract which are flavonoids, tannins and phenol compounds (Khaleel, et al., 2016; 2018b). There is, however, a need for further study so that the molecular mechanism of the observed protective effect and the actual active principles in the extract could be delineated.

\section{Conclusions}

The current study suggests that oral administration of the ethanolic leaf extract of $Z$. spina-christi is relatively safe and did not have deleterious effect on liver, kidney and on the serum biochemical parameters at the dosage investigated, but may have the tendency to cause reduction in the relative organ weights in rats. Studies for extended period are suggested to determine if the prolonged continuous use of the extract might cause challenge on the functional capacity of the organs. Histological studies are recommended for further assessment.

\section{Acknowledgements}

This research was funded by the Deanship of Academic Research at $\mathrm{Al}$ al-Bayt University (Project No. 7570/2015).

\section{Conflicts of interest statement}

The authors declare that there are no conflicts of interest.

\section{References}

Abu-Hamdah S, Afifi F, Shehadeh M and Khalid S. 2005. Simple quality-control procedures for selected medicinal plants commonly used in Jordan. Pharm Biol., 43(1): 1-7.

Ahmadvanda H, Tavafic M and Khalatbary AR. 2012. Hepatoprotective and hypolipidemic effects of satureja khuzestanica essential oil in alloxan-induced type 1 diabetic rats. Iran J Pharm Sci., 11: 1219-1226.

Alebachew M, Kinfu Y, Makonnen E, Bekuretsion Y, Urga K and Afework M. 2014. Toxicological evaluation of methanol leaves extract of Vernonia bipontini Vatke in blood, liver and kidney tissues of mice. Afr Health Sci., 14(4).

Ali AT, Penny CB, Paiker JE, Van Niekerk C, Smit A, Ferris WF, et al. 2005. Alkaline phosphatase is involved in the control of adipogenesis in the murine preadipocyte cell line, 3T3-L1. Clin Chim Acta, 354(1-2): 101-9.

Al-Qudah MA, Haddad MA and EL-Qudah JM. 2016. The effects of aqueous ginger extract on pancreas histology and on blood glucose in normal and alloxan monohydrate-induced diabetic rats. Biomed Res., 27(2): 350-356.

Andrew P, Adam LM, and Adam WW. 2005. Lactate-a signal coordinating cell and systemic function. $J \quad$ Exp Biol., 208:4561-4575.

Ashafa A and Olunu O. 2011. Toxicological evaluation of ethanolic root extract of Morinda Lucida (L) Benth. (Rubiaceae) in male Wistar rats. $J$ Nat Pharm., 2,108- 114.

Bannoth CK, Devanna N, Rani S, Krishna OS, Sree MG and Mallikarjun G. 2015 Anti-hyperlipidaemic activity of ethanol extract of whole plant of Corallocarpus epigaeus on wistar rats. Int J Res Pharm Sci., 6(1):35-43. 
Baranano DE, Rao M, Ferris CK and Snyder SH. 2002. Biliverdinreductase: a major physiologic cytoprotectant. Proc Natl Acad Sci U S A, 99 (25): 16093-16098.

Ben Younes A, Ben Salem M, El Abed H and Jarraya R. 2018. Phytochemical screening and antidiabetic, antihyperlipidemic,and antioxidant properties of anthyllis henoniana (coss.)Flowers extracts in an alloxan-induced rats model of diabetes. Evid Based Complement Alternat Med., 1-14

Dkhil MA, Kassab RB, Al-Quraishy S, Abdel-Daim MM, Zrieq R and Abdel Moneim AE. 2018. "Ziziphus spina-christi (L.) lea extract alleviates myocardial and renal dysfunction associated with sepsis in mice. Biomed Pharmacother., 102: 64-75.

El-Desouky WI, Abd El-Aleem IM and Saleh ES. 2014. Effect of ethanolic ziziphus (ziziphus mauritiana lam.) Leaves extract as radioprotector on some biochemical parameters of $\gamma$-irradiated male albino rats. Int $J$ Adv Res., 2(4): 1046-1057.

Etim O, Ekpo A, Bassey U and Akpan A. 2018. Effect of aqueous and ethanol leaf extracts of musa paradisiaca on serum protein, liver and kidney function in albino wistar rats. IOSR J Biotechnol Biochem., 4(6): 16-19.

Herrine SK. 2018. Medicinal herbs and the liver. Available online at https:// www.merckmanuals.com/home/liver-and-gallbladderdisorders/drugs-andthe-liver/liver-injury-caused-by-drugs. (Accessed 1 Nov 2018).

Ibrahim MA, El Nur E and Gameel A. 2016. Changes in body weight and serum biochemical parameters of Wister rats orally dosed with merua psudopetalosa (gilg and bened.) De wolff tuber extracts. Eur J Med Res., 4 (1): 52-59.

Ighodaro I, Innih S, Ogedengbe S and Amamina L. 2015, Chronic Toxicity Studies of Aqueous Leaf Extract of Voacanga africana in Wistar Rats. J Appl Sci Environ Manag., 19 (4): 639 - 646.

Khaleel SM and Haddadin MY. 2013. The enhancement of hawthorn leaf extracts on the growth and production of short chain fatty acids of two probiotic bacteria. Pak J Nutr., 12(2): 144-149.

Khaleel SM, Jaran SJ and Al-Deeb TM. 2019. Antimicrobial and lipid peroxidation inhibition potential of ziziphus spina-christi (sedr), a Jordanian medicinal plant. J Biol Sci., 19(2): 131-136.

Khaleel SM, Jaran SJ and Haddadin MY. 2016. Evaluation of total phenolic content and antioxidant activity of three leaf extracts of Ziziphus spina-christi (sedr) grown in Jordan. Br J Med Med Res., 14(6): 1-8.

Khaleel SM. 2018a. Anti- $\alpha$-glucosidase, anti- $\alpha$-amylase and antiinflammatory effects of leaf extracts of Ziziphus spinachristi (sedr) grown in Jordan. Res J Biol Sci., 13: 1-7.

Khaleel SM. 2018b. Studying the heavy metals composition and the impact of different common solvents on the extraction efficiency of phytochemical secondary metabolites from the leaves of Ziziphus spina-christi grown in Jordan. Pak J Nutr., 17(8): 392-398.

Khattab HAH, Al-Amoudi NS and Al-Faleh AA. 2013. Effect of ginger, curcumin and their mixture on blood glucose and lipids in diabetic rats. Life Sci J., 10(4): 428-442.
Kunle OF, Egharevba HO and Ahmadu PO. 2012. Standardization of herbal medicines- A review. Int J Biodivers Conserv., 4(3):10112.

Lavanaya S, Ramesh M, Kavitha C and Malarvizhi A. 2011. Haematological, biochemical and ion regulatory response of Indian major Carp, Carta catla during chronic sublethal exposure to inorganic arsenic. Chemosphere, 82(7): 977 - 985.

Leena K, Veena S, Arti S, Shweta L and Sharma SH. 2011. Protective role of coriandrum sativum (coriander) extracts against lead nitrate induced oxidative stress and tissue damage in the liver and kidney in male mice. Int J Appl Biol Pharm. ., 2(3):65-83.

Mehrdad M, Mozhgan GP, Sayed AT and Alireza J. 2011. Study of Histopathologic Changes of Zingiber extract on mice kidneys. International Conference on Food Engineering and Biotechnology - IPCBEE, 9: 16 - 20.

Mostafavinia SE, Khorashadizadeh M and Hoshyar R. 2016. Antiproliferative and proapoptotic effects of crocin combined with hyperthermia on human breast cancer cells. DNA Cell Biol., 35(7).

Nuhu AA and Aliyu R. 2008. Effects of Cassia occidentalis aqueous leaf extract on biochemical markers of tissue damage in rats.Trop J Pharm Res., 7(4): 1137-1142.

Nwanjo H. 2007. Studies on the effect of aqueous extract of Phyllanthus niruri leaf on plasma glucose level and some hepatospecific markers in diabetic Wistar rats. Int J Lab Med., 2 (2): $17-21$

Ogunka-Nnoka CU, Uwakwe AA and Nwachoko NC. 2012. Serum enzyme and histological studies of albino rat treated with ethanol/potash extract of Sorghum bicolor leaf sheath. Indian $J$ Drugs Dis., 1 (3): 74-78.

Osuigwe MJ and Margret N. 2017. Evaluation of the toxicological effects of Senecio aureus extract on the liver and hematological parameters in Wistar rats. Jordan J Biol Sci., 10(1): 29-32

Pieme C, Penlap V, Nkedoum B, Taziebou C, Tekwu E, Etoa F and Ngongang J. 2006. Evaluation of acute and subacute toxicities of aqueous ethanolic extract of leaves of Senna alata (L.) roxb (Ceasalipiniaceae). Afr J Biotechnol., 5: 283-289.

Renugadevi J and Prabu SM. 2010. Cadmium-induced hepatotoxicity in rats and the protective effect of naringenin. Exp Toxicol Pathol., 62:171-81.

Seufi A, Mohammed H, Moussa F, Seif El-Din A, El-Saadani M, Taha T and Hafez E. 2019. Protective Effects of the Aqueous Extract of Black Mulberry Leaves, Morus nigra, on Chlorpyrifos Toxicity in Male Albino Rats. Jordan J Biol Sci., 12(4): 385 393.

Tano KD, Kouadio JH, Yavo W, Djaman AJ and Menan EH. 2013. Toxic effect study of methanol extract of Terminalia glaucesens leaves following single or short-term repetitive oral administration in Swiss mice. Am J Biosci.1(4) : 85-90.

WHO. 1998. Traditional medicine regulatory situations of herbal medicines. A worldwide review, Geneva, 1-5. 